\section{UCDNN}

LIBRARY
University of Connecticut OpenCommons@UConn

Faculty Articles and Papers

School of Law

1979

\title{
A Utilitarian Theory of Judicial Decision
}

Thomas Morawetz

University of Connecticut School of Law

Follow this and additional works at: https://opencommons.uconn.edu/law_papers

Part of the Judges Commons, and the Law and Philosophy Commons

\section{Recommended Citation}

Morawetz, Thomas, "A Utilitarian Theory of Judicial Decision" (1979). Faculty Articles and Papers. 87.

https://opencommons.uconn.edu/law_papers/87 


\section{HEINONLINE}

Citation: 1979 Ariz. St. L.J. 3391979

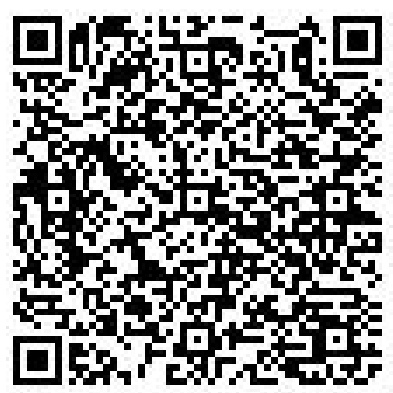

Content downloaded/printed from

HeinOnline (http://heinonline.org)

Mon Aug 15 17:12:14 2016

-- Your use of this HeinOnline PDF indicates your acceptance of HeinOnline's Terms and Conditions of the license agreement available at http://heinonline.org/HOL/License

-- The search text of this PDF is generated from uncorrected OCR text.

-- To obtain permission to use this article beyond the scope of your HeinOnline license, please use:

https://www.copyright.com/ccc/basicSearch.do?

\&operation $=$ go\&search $\mathrm{Type}=0$

\&lastSearch $=$ simple\&all=on\&titleOrStdNo=0164-4297 


\section{A Utillitariam Theory of Jundiciml Decision}

\section{Thomas Morawet $z^{\circ}$}

\section{INTRODUCTION}

The nature of judicial decision-making is a major preoccupation of contemporary jurisprudence. Prominent and influential writers like Ronald Dworkin and John Rawls ${ }^{1}$ have taken the position that no utilitarian account of judicial decision-making, or of moral decision-making in general, can work. My main purpose in this article is to outline and explain the main features of a plausible utilitarian account. In doing so, I shall rebut some of the most common criticisms but I shall not try to offer a full defense of utilitarianism against its most sophisticated critics. Rather, this can be seen as a preparatory study for such a defense.

The question "What is the nature of judicial decision-making?" is ambiguous. It may be a question in pursuit of a description of what constrains judges or one seeking criteria for what counts as justification for judicial decisions. I shall take it as the latter, as a question about the criteria by which judicial decisions are to be assessed. Even so, the question is still ambiguous. It may be a question about the criteria of what is permissible in judging or about the criteria of what is desirable (or optimal). One can argue that a positivistic account of decision-making, ${ }^{2}$ like that offered by H.L.A. Hart, ${ }^{3}$ includes an account of what is permissible. Accordingly, Hart's account implies that it is impermissible for a judge to violate the formal rules which instruct him how to carry out his job and which limit his power. Within his delegated duties, he may use discretion to decide hard cases by appeal to relevant moral and factual considerations.' Al-

\footnotetext{
* Professor, University of Connecticut; A.B., 1963, Harvard; J.D., 1968; M. Phil., 1968; Ph.D., 1969, Yale.

1. See R. Dworkin, Taking Rights Seriously vii-xv (1977); J. Rawls, A Theory of Justice 60-65 (1971).

2. In general, positivists define law as a system of rules or general commands backed by the threat of enforceable sanctions. H.L.A. HART, The CONCEPT OF LAw 20-25 (1961). Hart's sophisticated description of the structure of a legal system stresses the interrelation of two kinds of rules, primary rules which prescribe restrictions on the actions of citizens generally and secondary rules which instruct officials how to make, change, and administer the primary rules of the system. $I d$. at $\mathrm{ch} . \mathrm{V}$.

3. Id. at chs. IV - VI.

4. I am using the term "discretion" here in the uncontroversial sense in which the judge is asked to bring forth reasons in exercising his judgment to decide hard cases. The question whether a judge has discretion in a stronger sense than this is controversial between Dworkin and Hart.
} 
though the distinction between what is permissible and what is optimal is sometimes hard to draw and sometimes controversial, ${ }^{5}$ I offer utilitarianism as a theory of the second kind. It is a theory of optimal decisionmaking, a theory about criteria for evaluating judicial decisions within the range of what is permissible.

\section{Legal Reasoning as Moral Reasoning}

\section{A. Theory of Moral Decisions}

A moral decision, as I shall use the term, is any decision which can reasonably be expected to affect persons in a beneficial or harmful way. Judicial decisions are moral decisions because they affect persons by benefiting or harming them. A theory of judicial decision will therefore be a theory about moral decisions which gives special attention to the position and power of judges. Our job is to locate the very general moral standards which judges are expected to deploy and which are deployed in the criticism of judges. To find such standards is to put forward a theory about justification, an analysis of what it is that counts as justification for a judicial decision and as justification in criticism.

Any search for critical standards, whether for legal reasoning or for moral reasoning, presupposes that two extreme views are untenable. These are the views (1) that a simple decision procedure exists for every case that may come up for decision, i.e., that there are no hard cases, and (2) that "anything goes" in legal or moral reasoning, that there are no critical standards to be found.

(1) It is easily seen why we are not likely to find a decision procedure for moral problems. Suppose, for example, that a president or legislator must decide whether to recommend using particular funds to improve a defensive missile system rather than to raise price supports for farmers. A moral debate about this decision will have to take into account many things: the likelihood that new defense systems will be needed for security, predictions about how such systems will be used, the economic circumstances of farmers, the effect on food prices, and many others. Such decisions are characteristically hard for two reasons. The first is that such factual determinations are complicated and uncertain. The second is that, even if such factual predictions could be made with certainty, different persons would weigh their moral importance (and strategic relevance, etc.) differently. This is not only true in a complex governmental decision. It is equally true in the case of a simple decision to break a promise to A (to

5. Dworkin, for example, often says that in saying that a judge must emulate a judicial Hercules, he is describing the judge's duty. See R. DworkIN, supra note 1, at 105-30. If this is so, the judge has a duty to do what is optimal and the distinction between what is permissible for him and what is optimal for him vanishes. I am assuming the distinction does not vanish. 
meet $\mathrm{A}$ for lunch, for example) to help friend $\mathrm{B}$ (who needs help moving furniture). This is a fairly trivial case because the moral consequences of breaking or not breaking the promise are likely to be small, but even here the same difficulties are present. I cannot anticipate the results of my acts with certainty, and I am not likely to weigh the expected consequences of either action exactly as another person would. To suppose that there is a decision procedure for moral problems which eliminates these difficulties and to seek that procedure is to pursue a chimera.

Notice that the difficulties are not relieved if one believes that morality consists in following rules which are strict and unqualified, rules like, "Always tell the truth," "Never take the property of another without permission," "Keep your promises," and so forth. There is still the problem of what to do when the rules conflict. What if telling the truth involves breaking a promise? One may argue that there are other rules which specify which rules have priority over others. An example would be, "Keep promises unless they involve lying because truth-telling has priority." But surely this is not very persuasive. There are some cases, easily imagined, in which a lie is justified because the adverse effects of breaking a promise would be very dire and other cases in which this is not so. It will now be suggested that this only shows that the rules need to be refined further. But counter-examples will always be available; the task of refinement can never be completed.

(2) If it seems plausible that there cannot be a moral decision procedure which prevents real dilemmas from arising, it is also plausible that not anything goes, that not all ostensible moral opinions about situations are intelligible as moral opinions or, if intelligible, are capable of being seriously entertained. For example, someone who said that in general it is morally good to break promises or to maim philosophers would simply not be understood as holding a permissible and interestingly original moral view. Instead, he would lead us to think either that he was misspeaking (did not say what he meant or didn't understand how to use the language) or that he could offer a special ulterior justification, e.g., that promisebreaking tests the mettle of the would-be promisee, benefiting him by making him self-reliant and tolerant of disappointment. ${ }^{7}$ Such a reason may still be unpersuasive and we may dismiss it, but it is intelligible while the bare original claim is not. Similarly one who argues for the moral merits of a policy which is said both to increase the likelihood of war and

6. Kant, among others, claims that such a procedure exists, and that it generates clear solutions, at least with regard to promise-keeping. I. Kant, Foundations of the Metaphysics of Morals (L.W. Beck trans. 1959). [Originally published in German in 1785.] In discussing objections to utilitarianism in Section 2 of this chapter, I discuss the view that to take promise-keeping seriously as a moral commitment is to be committed to keep all promises. I criticize this view, and the criticisms are relevant to Kant's position.

7. A third possibility is simply to regard the speaker as crazy. 
decrease the availability of goods, puts us on notice that he will offer a special reason why such consequences are to be sought.

There are two ways in which a moral claim, a claim that an act would be morally good or bad, can seem unintelligible. The first, as we have just seen, is a claim that endorses an act which is prima facie bad, and does so for no redeeming ulterior reason. The second is a claim to which moral considerations simply seem irrelevant. The claim that it is good, in itself, to clap hands or make objects blue is a claim of this kind. Again, the claim can be redeemed as a moral claim only if a special kind of second-level justification is given, for example, that clapping is healthful exercise or that blue is an especially pleasing color. ${ }^{8}$

These very general remarks suggest some general conclusions about moral reasoning because they lead us to ask what feature of moral claims makes them understandable as moral claims. The examples suggest that there is some connection between the judgment that an act is morally good and the judgment that someone or other is benefited by it. What is peculiar about the claim that maiming or clapping hands is good is that there is no connection to benefit, and the criterion for a relevant explanation is that it establishes some connection of this kind. I am using "benefit" in the very general sense of "affecting someone in a positive way." The examples above illustrate this point. The person affected positively may in some cases be the actor himself. It may be commended to me as morally good to cultivate my talents not because others will gain but because I will be better as a result. ${ }^{9}$ Just as there is a connection between goodness and benefit, there is a parallel connection between the judgment that an act is morally bad and the judgment that someone is harmed by it. So far I have not tried to examine the connection beyond suggesting that it is a necessary minimal condition of sincerely calling an act "good" to think that someone is benefited by it, etc.

I am not at all suggesting that there is a decision procedure for determining what things are benefits or for weighing benefits. I cannot expect that another person will agree with me on all my claims about what is beneficial or on my judgments about relative benefit, but I can expect that the reasons I give will tend to be understandable to him and vice versa. I can also expect that various particular and general differences in factual belief will often underlie and be available to explain our differences when they arise. I may believe, for example, that it is bad to discipline children

8. This argument is elaborated and defended in my paper, Goodness and Benefit, $9 \mathrm{~J}$. VALUE InQuiry I (1975). See also Foot, Moral Beliefs, in Theories of Ethics 83 (Foot ed. 1967).

9. Note that not all consequences which are morally significant when A brings them about for B are also morally significant when $\mathbf{A}$ brings them about for himself. It may be morally praiseworthy to feed a hungry child but not to have a meal when one is hungry oneself. Significantly moral selfregarding acts require a special account. 
by locking them into rooms; someone else may defend it on moral grounds. The difference between us may well turn to be a difference in our beliefs about the psychology of children. I may believe that such punishments create unresolved anger and mistrust between parents and children and are not effective in bringing about greater responsibility. A contrary belief about psychological facts will most likely lie beneath a contrary moral judgment.

We can also see why there is rough congruence in moral judgment. ${ }^{10}$ Each person's notion of benefit has two components, some sense of the ways in which all persons are benefited in similar ways because they have similar needs, wants, and pleasures, and some awareness of the range of different personal ways in which persons are benefited-and of the reasons for those idiosyncracies. The fact that we successfully anticipate and understand the reasons which others give when benefit is discussed, whether we agree in our conclusions or not, is evidence that we have a shared sense of what benefit is." To say that terms like benefit and harm (and goodness and badness) refer to a range of factually specifiable consequences for persons in general is to give a naturalistic account of them. ${ }^{12}$ It is naturalistic because it says that certain substantive things or kinds of things are essentially good things to bring about and because it thus ties the moral notion of goodness to a particular factual content. By contrast, a nonnaturalistic account would expalin the use of a term like goodness by a formal feature, for example, by saying it is the expression of a strong preference.

To summarize, I have suggested by example why there is not likely to be a decision procedure for moral reasoning and why, at the same time, there are some substantive standards for what counts in moral

10. What is the community of moral judges to which "our" refers? That community is certainly not defined by or limited to those who share a particular language. Rather, it is characterized by those who can recognize and understand moral situations and dilemmas, whether they appear in daily life, in Plato, Rousseau, Proust, Kierkegaard, Kawabata, or a contemporary mystery novel. The members of such a community will decide moral cases differently but will share criteria for the relevance of moral reasons and will grasp the sources of their disagreement. Obviously, this notion begs many questions about criteria of membership in such a community, about reciprocal understanding, and so on.

11. This is not a special feature of the notions of harm and benefit but a feature of all notions, from such concrete ones as that of chair or food to such abstractions as happiness or liberty. I am here making a logical point: for terms to have common usage they must be understood in more or less the same way by users. Related arguments are to be found in L. Wittgenstein, Philosophical INVESTIGATIONS (1953).

12. The first step of a naturalistic account of our criteria for benefit would be to examine shared desiderata of survival. But an account of survival is only a minimal account of benefit. Note also that a naturalistic account of benefit would attend to differences among persons as well as similarities; $A$ may naturally be benefited by $X$ while $B$ may naturally be benefited by $Y$. These are facts which they may understand about themselves and about each other, facts which can then be a basis of moral action. 
reasoning ("not anything goes"). This analysis depends on the link between goodness and benefit and on the relative determinateness of the notion of benefit. While there is no objective measure for benefit, those who discuss benefit reach mutually understandable conclusions on the basis of shared criteria.

\section{B. Responses and Objections}

Before pursuing this argument further, I want to anticipate some responses and objections. (1) A possible response to my analysis is this: "If there is no decision procedure for moral reasoning, so much the worse for moral reasoning. Lacking a decision procedure, it is a defective form of reasoning." This response imposes an unreasonable Procrustean demand. There may be imagined advantages to a decision procedure for moral judgment just as there may be such advantages to knowing the future with certainty. (It takes little imagination to see there may be disadvantages as well.) But the envisaged form of life is not our form of life nor is it a form of life which persons have ever had or can ever expect to have.

(2) A variation on the first response is that if no decision procedure exists, moral and legal reasoning are not worth serious study. The investigation becomes a topographic survey of the terrain, an account of what persons happen to do when they make moral or legal judgments, and of whether they happen to agree or disagree. If we could generate a decision procedure, this would give a test for determining when judges (moral or legal) do their job badly or well. In the absence of one, we have no such test.

This objection rests on a misunderstanding. The misuse of the metaphor of topography shows this clearly. The "terrain" is not just surveyed and described. The moral and legal judgments made in particular cases are the philosopher's raw material, not his end product. He uncovers not only the judgments persons make but the standards which they use to arrive at judgments and to criticize the correctness of judgments.

This is a general point about practices in which judgments can be made by using objective standards but in which there is, nonetheless, no decision method of deciding hard cases unequivocally. Just as there are standards for judging satisfactory moral decisions, there are standards for judging satisfactory cars, good cuisine, outstanding football playing, and good driving. None of these involve a decision procedure which yields the same judgment by all judges or in all contexts. There will be unresolved controversies about all these matters. None, on the other hand, involves license on the part of the judge to say anything he pleases on whatever grounds he may choose at random. It would not make sense to judge football by the standards of ballet. A different way of making my point is that it is wrong to say that judgments are either objective or subjective if 
"objective" means "made according to a decision procedure" and "subjective" means "made without recourse to publicly shared standards." Judgments which are involved in most activities are neither.

(3) Still another objection says that unless I can claim that there exists a decision procedure (that moral and legal judgments are "objective") I can neither expect nor demand that others will share my views or my conclusions. This objection is in fact very similar to the second objection. What we have seen is that while I cannot expect others to reach all the same specific judgments that I reach, I inevitably expect them to have the same standards of judgment. I will, in particular, expect others to have the same criteria for what kinds of reasons are relevant, to weigh reasons in anticipatable ways, and to justify odd-sounding conclusions in anticipatable ways. This expectation is not coercive. It is not a "demand." Rather, it is a fact that unless they act in this way, they will not be participating in a shared activity ("practice") of judging. We will not be talking about the same activity. ${ }^{13}$

(4) A point to remember about legal and moral reasoning is that we expect decision-makers to act in a disinterested way. This means that in making a moral judgment, one must put aside one's own particular interest in the result and attend to benefits and harms for others. ${ }^{14}$ When we talk about moral reasoning and moral action, we presuppose that individuals have the capacity to lay their own immediate interest to one side; a psychological theory which denies this will deny the possibility of moral judgment. ${ }^{15}$ This matter is particularly clear in the judicial context. The fact that a decision may help or hinder a judge in his personal or professional interests must be irrelevant to his decision. (This is a basic standard, whether or not judges in fact lapse in this way.)

13. There is a sense in which certain odd-sounding claims about benefit, harm, and value may be intelligible as pathology. For example, the claim that clapping hands is harmful and dangerous, and therefore morally bad, may have to do with the particular significance that clapping has for the victim of a psychological disturbance. But this is not to understand the claim as a debatable moral claim made on the basis of criteria.

14. To choose disinterestedly is to choose without any particular or special regard for oneself. This is not to say that effects on oneself must be discounted completely. Rather, they must be treated with the same regard as benefits to others. Kant makes the general point about disinterest, saying that moral action involves treating others as ends in themselves and not as means toward achieving one's own interests. I. Kant, Foundations of the Metaphysics of Morals 56-57 (L.W. Beck trans. 1959). [Originally published in German in 1785.] A form of the basic imperative of morality is to treat others in accord with a rule which one can will universally as a rule of behavior.

15. Note the distinction between the deterministic view that individuals must always act in their own interest and the recommendation that individuals always act in their own interest even though they have the choice of not doing so. A variation of the latter view is the theory that it is always in one's interest to act morally and that one serves self-interest (at a second level) by being moral (on the first level). 


\section{Summary}

I have tried to lay a foundation for a theory of judicial decisions by sketching the outlines of a theory about moral decisions. My assumption in doing so is that a judicial decision is a kind of moral decision, that what makes a hard case hard for a judge is that it presents a moral dilemma, or at least a difficult moral determination. If this is so, a judge can ignore the moral dimensions of his role only at his peril.

The moral theory we have considered has its beginnings in some simple observations. It says that there is a logical connection between moral judgments and factual judgments about benefit and harm, and that the moral goodness of an action or decision depends on its beneficial and harmful consequences. The theory formulated in this way will provoke contradictory responses. One response is that it is obvious and empty. Who would have thought that judges ought to function in any other way than to bring about benefit and prevent harm? It will be said that this is true and absurdly uninformative. A second, and very different, response is that the theory is radical and preposterous. Surely judges are constrained by standards other than the injunction to do good by maximizing benefit and minimizing harm. The result of judges following this rule would be chaos, the collapse of the institutions of law.

Clearly, the theory needs elaboration as an informative account of the standards which underlie moral and legal judgment. The theory is best explained by uncovering and answering various objections to it. I shall approach this job in three steps. First, I will fill out some of the details and applications of the theory by showing something of its pedigree. That is, I will show why it is a kind of utilitarian theory. But utilitarian theories are a family of different theories about moral reasoning and I shall show how our theory is related to other utilitarian theories. Second, I will look at some general objections which have been raised against utilitarianism and see which objections are relevant to our account. I will consider how those objections can be met. Third, and most important, I shall discuss the application of a utilitarian theory of moral reasoning to judicial decision-making.

\section{Utilitarianism: Criticisms and Corrections}

The motive behind nineteenth-century utilitarian theories is altogether different from our own motive. Jeremy Bentham, the "inventor" of utilitarianism, tried to devise a decision procedure for moral judgment, an intellectual strategy which would generate uniform objective solutions for moral problems and which would reduce all factors in a moral question to a common measure. ${ }^{16}$ The present theory makes no such claims. It is

16. J. Bentham, Principles of Morals and Legislation (1948). [Originally published in 1789.] 
not a mechanism for reforming the practice of moral reasoning; it is intended instead as a reminder and a perspicuous rendering of the standards which already inhere in the practice of moral reasoning as it is generally carried on. The notion of benefit is a notion we already have and employ. Let me explain these matters by raising particular points of difference.

In classical Benthamite utilitarianism, the goal of morality is to maximize pleasure and minimize pain. ${ }^{17}$ Pleasure and pain are taken to be the common denominators of all morally relevant experiences. For other utilitarians influenced by Bentham, maximizing happiness ("the greatest happiness for the greater number"18) is the goal. It was quickly pointed out that there were difficulties in the Benthamite strategy since (a) pleasure, pain, and happiness are not measurable and (b) there are other moral goals besides pleasure, happiness, and the avoidance of pain. For example, it is easy to see that the pain of serious injury exceeds the pain of an unconvenient change of plans; an act which has the consequence of causing serious injury is therefore, for moral reasons, to be seriously avoided. But the question, how much worse is a serious injury, is unanswerable if it is a demand for a numerical answer. Much of Bentham's strategy seemed to presuppose that these factors can be quantified. The second objection can be illustrated by the moral value assigned to courage or self-sacrifice. Actions of this kind may benefit others and have altruistic motives, but they may do so by adding to the sum of dignity and self-respect in the world rather than to pleasure and happiness. ${ }^{19}$

Objections of these kinds are irrelevant to a theory based on benefit and harm. The theory does not claim to give a decision procedure and acknowledges that benefit and harm are not measurable. What degree of agreement may exist in moral judgment is a function of the way (independent of theory) persons experience benefit and harm and not a function of mathematical reforms in judgment generated by the theory. The theory meets criticism (b) by demonstrating that the notion of benefit encompasses the moral goals which happiness, pleasure, and the avoidance of pain leave out. For example, by teaching someone self-discipline we may be benefiting him and therefore performing a moral act whether or not there is a net increase in pleasure or happiness. ${ }^{20}$

17. Id. at chs. III, $\mathrm{V}$.

18. 10 J. Bentham, Works 142 (1830). See J.S. Mill, Utilitarianism passim (1973). [Originally published in 1861.1

19. See R. Brandt, Ethical Theory ch. 15 (1959) for an account of these criticisms.

20. Two points. This argument can only be carried out piecemeal. As each particular moral goal is considered, it can be argued that that goal is compatible with a theory of benefit and not with a theory of pleasure. The possibility of a counterexample (a moral goal which is not beneficial) cannot be ruled out but the burden rests with those who would disprove the theory. Secondly, note that it is always possible to save a theory that happiness is the sole moral goal by redefining happiness to coincide with the sum of moral goals. 
Modern critics of utilitarianism offer a criticism which is a variation of one just considered. Critics such as Richard Brandt and John Rawls argue that utilitarians advocate maximizing social welfare and that this leaves aside other important moral goals. ${ }^{21}$ Brandt offers the example of an aged parent who is artificially kept alive at great expense and with a heavy emotional toll on his family. Brandt argues that the utilitarian would find no social welfare - and therefore no value - in keeping the parent alive. ${ }^{22}$ Rawls argues, to the same effect, that a utilitarian would be committed by his theory to breaking his promises whenever some social welfare was to be attained by doing so..$^{23}$

Such criticisms are not relevant to the theory of benefit and harm. Note first that the situations described or suggested by Brandt and Rawls in the examples are potentially very difficult. No adequate theory can generate easy answers and any adequate analysis will have to attend, more than Brandt and Rawls do, to the details of the particular situation. Where the prospect of survival, or of recovery of consciousness, or of diminution of acute pain is slight in the case of the aged parent, the dilemma will be hard. Analogously, there are cases in which promise-breaking is justified even though, in the absence of other considerations, there is likely to be harm to the promisee who has relied on the promise. For the utilitarian, promise-breaking will be justified only to the extent that the benefit to be derived through the breach overrides this harm. Thus, the first mistake that Brandt and Rawls make is supposing that the answers to such dilemmas are obvious (that one preserves life at all cost, that one keeps all promises) and that the utilitarian answer obviously is the opposite of the correct answer.

The criticisms involve a second mistake which is more general and more important. They presuppose that all utilitarian theories (a) say that the moral worth of an act is determined by its consequences for welfare and (b) assign a specific weight to the relevant consequences. But the theory of benefit and harm explicitly does (a) and not (b). The significance or weight given to each factor in any moral situation is informed by our intuitions and by the usages which exist independently of the theory. Thus, in . Brandt's case of the aged parent, the theory alone tells nothing about whether the benefit to the parent (and to relatives) of extended survival does or does not outweigh the suffering, expense, etc. All it tells us is that when we do make a moral judgment, we must attend as carefully and disinterestedly as possible to considerations of benefit and harm, for what else is relevant? It is certainly possible and indeed likely that survival for

21. See Brandt, Toward a Credible Form of Utilitarianism, in Morality and the Language of Conduct 107 (1963); Rawls, Two Concepts of Rules, 64 Philosophical Rev. 3 (1955).

22. Brandt, supra note 21 , at 110 .

23. Rawls, supra note 21 , at 17. 
one day may outweigh in benefit a great deal of suffering and long-term financial hardship; the utilitarian whose theory is based on benefit and harm would not necessarily say otherwise.

Having answered one set of criticisms, we must consider the objection that utilitarianism is an inadequate theory of moral reasoning in need of completion. On this view it is a vague or weak theory which instructs us to look for benefit and harm but which seems to allow almost anything to count as benefit and harm. Critics insist that it needs to be supplemented or replaced by a theory of rules (Rawls) or a theory of rights (Dworkin) which would identify particular kinds of moral consequences which would have priority over others. An example would be a set of moral rules which said that the benefits of liberty always have priority over material benefits.

I shall look in detail at theories of this kind but a general response is that my theory is only as elastic (or non-specific) as the notion of benefit and that the elasticity of the notion must not be exaggerated. The philosopher's job doesn't end with uncovering the utilitarian principle, the relation of goodness and benefit. It also involves doing what J. L. Austin calls "linguistic phenomenology"24 on the notions of benefit and harm to determine what sorts of things count as benefit and how much divergence exists and can exist among those who use the notion. Those who find utilitarianism an inadequate theory seem to assume that this enterprise will yield little.

One form of this criticism is that unless we can say more about benefit we will have to give up making interpersonal comparisons. Unless there is an objective measure of moral worth, formulated in rules of justice as a theory of rights, we must concede that what benefits a person is only what he thinks benefits him. Once we concede this we are no longer able to make moral judgments which are anything more than judgments about preference satisfaction. Accordingly, Ronald Dworkin claims that utilitarian theories collapse into theories which determine moral goals by looking at the preferences of those affected by the action. ${ }^{25}$ This, Dworkin argues, entails fatal difficulties which will affect any theory in which preferences are a criterion for determination of goals, for example, a theory which says that happiness is to be maximized. Surely not all happiness is to count; what about the happiness of the sadist who enjoys the suffering of others? The same objection affects a theory of social welfare as long as social welfare is measured by preferences, by what persons claim (or think) they want. A society which has never experienced free speech or selfgovernment may not include aspects of liberty in its notion of welfare. This should not mean that we must leave it out of account in considering that

24. J. Austin, Philosophical Papers 130 (1970). G.E.M. Anscombe makes a similar point in Modern Moral Philosophy, 33 Philosophy 1-2 (1958).

25. R. DWORKIN, supra note 1, at 233-38. 
society's welfare. This criticism clearly indicts a theory of benefit if the theory defines benefit by appeal to preferences.

Obviously, it is a sound observation that a theory which would define moral action in terms of maximizing personal preferences is a defective theory. But a theory which talks of maximizing benefit is not subject to this objection. The theory makes clear that, even if we assume that most persons most of the time are good judges of what is beneficial or harmful to them, being benefited and thinking that one is benefited are different matters. It is always possible to be mistaken. To the extent that these are different matters, to the extent that someone's sense that something will benefit him is only one factor among others in my judgment about what will benefit him, the sort of objection Dworkin presents is irrelevant. But, at the same time, a theory which meets the objection in this way invites the criticism that it is paternalistic. When a moral or judicial decisionmaker claims that a decision will benefit $A$ and $B$ in spite of what $A$ and B happen to think or prefer, his claim is frankly paternalistic. But is it to be rejected because it is paternalistic?26 In responding, we need to distinguish two points. One is that there are perfectly ordinary situations in which an external observer may be expected to know what is going to benefit or harm a person better than that person. The observer may, for example, have special expertise. He may be a doctor, lawyer, engineer, or psychiatrist who knows that if the agent proceeds as he intends the consequences will, by the agent's own eventual admission, be disastrous. Even if it is conceded that paternalism has this limited justification, it will be said that paternalism is easily abused and the moral or legal judge will be tempted to override the preferences of the person affected even when he does not know better. Even more importantly the procedure seems to ignore the important benefits of being able to choose for oneself even when one chooses wrongly.

A brief answer is that any theory may be abused; it is no part of a theory to preempt its abuse. But, if we put this aside, the objection is important because it is related to one of the most general and pervasive criticisms of utilitarianism, that no utilitarian theory can give proper attention to the moral importance of liberty and fairness.

So far, we have clarified the theory that moral reasoning is in fact a matter of reasoning about benefit and harm by contrasting it with other kinds of utilitarian theories. Thus, it does not reduce moral considerations to a common denominator like pleasure, happiness, or social welfare. In doing so, it exempts itself from the criticism that it oversimplifies moral dilemmas or that it leaves out of account certain intuitions about the moral importance of life or of promises. It is, in other words, not a strongly

26. See Feinberg, Legal Paternalism, I Canadian J. Philosophy 105 (1971). 
revisionist theory which says that our ordinary moral intuitions are too complex and inconsistent; rather, it is a theory which takes up these intuitions and shows how they are to be reconciled. But if it is not an overly strong theory, it is also not a weak theory which says that the only justifiable goal identifiable in moral reasoning is the satisfaction of preferences (or want-satisfaction). The theory, in invoking the notion of benefit, uses a notion which is strong enough to be used in criticism of preferences. It is a part of the theory that we are able to explain those situations of moral judgment in which we say that, wants and preferences notwithstanding, it is in the interest of persons to be compelled, for example, to go to school or to confront their responsibility, etc.

\section{Utilitarianism AND LiberTy}

Perhaps the most frequent and vigorous criticisms of utilitarianism say that no utilitarian can give a satisfactory account of the moral importance of liberty. ${ }^{27}$ Such critics emphasize that this point is particularly important when we are concerned with the morality of political or legal decisions. It is argued that an overriding interest in maximizing benefit and minimizing harm will inevitably lead (a) to decisions in which liberty is undercut for the sake of so-called benefit and therefore (b) to a situation in which persons are treated unfairly. The utilitarian is said to be led to these unfortunate results in two ways. First, his method of resolving cases will be to weigh liberty - when he considers it at all - as just one of several benefits which, as a class, are to be maximized. A failure to secure liberty may be offset by beneficial gains of other kinds. For example, a curtailment of free speech may be justified by an increase in material wealth overall. Second, the practice represented in this method will be to impose a judgment about maximal benefit on others; this will inevitably undercut liberty to choose how one will live and even to choose to harm oneself. Thus, these critics say that a utilitarian approach undercuts liberty in two significant ways, by arrogating to the decision-maker unlimited decisionmaking power and by the particular decisions which he is likely to make. It follows that a theory which takes liberty seriously will have two features. It will place "jurisdictional" limits on decision-makers, limits which respect the inviolable liberties of individuals, and it will involve criteria for decision-making which will give special priority to liberty over and above consequences of benefit and harm.

The criticisms, as I have summarized them, are well-represented by Ronald Dworkin's Taking Rights Seriously and John Rawls's $A$ Theory

27. See, e.g.. J. RAwLS, supra note 1 at 22-33, 183-92 (1971); R. DwORKIN, supra note 1, at 81130,266-78. Dworkin, unlike Rawls, opposes utilitarianism to theories of rights rather than to theories of liberty but the criticisms are similar. 
of Justice. ${ }^{28}$ Dworkin makes the first suggestion, that in a correct theory of moral/judicial decision-making, enjoying liberty is not just one kind of beneficial consequence among others. Rather the possession of rights by individuals is a kind of veto upon decision-making which individuals have implicitly and which decision-makers must respect. ${ }^{29}$ Liberty, if it is understood to be the enjoyment of matured and concrete rights, ${ }^{30}$ constitutes an outer bound on permissible interventions in persons' lives. Dworkin argues that this notion of a boundary limiting what decision-makers can and cannot alter is one which utilitarians cannot take seriously.

The second suggestion is made by Rawls when he offers criteria for just decision-making. One criterion is that considerations of liberty be "prior in lexical ordering" to considerations of welfare. ${ }^{31}$ This means that the goal of insuring for each participant in a practice (e.g., each member of a society subject to a legal system) the most extensive liberty which is compatible with a like liberty for all ${ }^{32}$ cannot be overridden in the pursuit of any allocation of wealth in the form of "primary goods" (largely material wealth), however abundant and however equitable the distribution may be. The point of both Dworkin's and Rawls's arguments is that a theory founded on liberty (or rights) ${ }^{33}$ as opposed to a utilitarian theory accurately gives the standards implicit in moral judgments, particularly moral judgments relating to public affairs.

This indictment raises several independent questions. Do the critics represent utilitarianism correctly? Do their own theories yield clear alternatives? I shall argue that the critics misrepresent utilitarianism as it can be construed along the lines of the theory of benefit and offer alternatives which are themselves unclear, alternatives which may in practice give the same results as the utilitarian theory. Consider the following points.

(1) One assumption which may be implicit in these criticisms is that liberty is not the sort of good which a utilitarian can take seriously. This means that utilitarians characteristically attend to tangible and material ends and prefer ends which are quantifiable; the paradigm is the accumulation of property. It is clear that this accusation misfires. The notions of benefit and harm are neutral with regard to the tangibility of ends. (Even classical utilitarians spoke of pleasure and happiness, and what is less tangible than pleasure?)

There is a more subtle form of the criticism. Liberty, unlike pleasure or happiness, is not so much a goal of action as an aspect or condition of

\footnotetext{
28. R. DWORKIN, note 1 supra; J. RAWLS, note I supra.

29. "Individual rights are political trumps held by individuals." $R$. Dworkin, supra note 1 , at xi.

30. Id. at $90-94$.

31. J. RAwLS, supra note 1 , at $40-45,60-65$ (1971).

32. Id. at 60 .

33. See note 27 supra for the difference between Rawls and Dworkin.
} 
acting and living. ${ }^{34}$ When we speak of liberty, we are thinking of the needs of persons as actors, as persons who make choices and are aware of doing so. This abstract conception stands in contrast to the equally abstract conception of persons as passive collectors of goods. A moral theory which has a place for liberty must be based on an active rather than a passive conception of persons.

Let's see how a utilitarian might try to meet this criticism. Obviously, he needs a rich conception of benefit and harm. Benefits are not just goods received and harm is not just material injury or deprivation of goods. One is benefited whenever one is allowed or encouraged to act in a way that furthers self-esteem, self-improvement, the development of capacities, and the expressing and testing of one's thoughts. To be provided with the conditions of living in this way is a benefit just as it is a benefit to have food, shelter, health care, and love..$^{35}$ I shall call benefits of the first kind "active benefits" and the second kind "goods." It seems clear that active benefits can be secured only indirectly, by setting conditions for living well in these respects. The initiative for living well lies with the individual. ${ }^{36}$ This does not mean, however, that these benefits are secured only by governmental self-abnegation, e.g., by non-interference with speech, assembly, etc. They are also served by such affirmative interventions as compelling public education, providing mental health care, and preventing persons from interfering with the exercise of speech, etc., by others.

The critics are correct that it is an important feature of an adequate moral theory that benefit and harm be generalized in this way. But there is no reason to think that a utilitarian theory of benefit and harm cannot meet this challenge.

(2) The criticism may be made in a different form, drawing attention not to the kinds of benefits the utilitarian can include within his theory but to the way in which he says we compare benefits in moral reasoning. Even when critics concede that utilitarians allow some weight to be given to the exercise of liberty, to self-esteem, and so forth, they claim that utilitarians will not be able to give them enough weight to generate a satisfactory account of their place in moral reasoning. This, we have seen, leads Rawls to say that there is a lexical ordering among principles of justice and that liberty has priority over wealth. ${ }^{37}$

34. This is not to deny that securing liberty may be the goal of political activity. But it is a goal only in the sense that it is sought as a condition or aspect of other contemplated future activities. The notion of liberty which I am using combines, I think, what Isaiah Berlin calls negative liberty ("freedom from . . .) and positive liberty ("freedom to ..."). Liberty as a way of acting is positive liberty; liberty as a condition of acting is negative liberty. See I. BERLIN, Two Concepts of Liberty, in Four Essays ON LIBERTy 118 (1970).

35. I am not suggesting that the two kinds of benefits are commensurable. See the discussion which follows in the text.

36. Again, this is Berlin's notion of positive liberty. See note 34 supra.

37. J. RAWLS, supra note 1 at $42-45$ (1971). 
This objection is a variation of one we have already considered. The critic persists in attributing to the utilitarian a particular and a counterintuitive assignment of weights to benefits. Once it is conceded that the theory describes moral reasoning as the weighing of benefits but imposes no weighing of its own, the objection disappears. It is entirely compatible with utilitarian theory that the moral decision-maker have a deep-seated commitment to "active benefits" and regard the recognition and fostering of the conditions of liberty as an extraordinarily important, and ordinarily supervening, way of conveying benefits. A moral/judicial decision which ignored or undervalued this range of considerations would be objectionable not because it was any more or less an instance of utilitarian reasoning but because it would rest on a mistaken conception of benefit. ${ }^{38}$ If Rawls or Dworkin were to fault utilitarianism for failing to guarantee that liberty will be a supervening consideration, they would be looking for the guarantee in the wrong place. Recognition of the importance of liberty will be part of an adequate analysis of benefit.

There is one way in which the more general notion of benefit fits moral judgment better than a set of rules which give priority to liberty. There will always be special situations which are counterexamples to such rules, situations in which material needs are so urgent that a curtailment of liberty is morally justified. Governments justifiably declare curfews in emergencies, censor newspapers during war, and appropriate private resources to prevent starvation. A general rule of thumb that active benefits are supervening over goods is compatible with the recognition that in exceptional cases active benefits may justifiably be suspended to secure survival or minimal welfare. (This is analogous to the observation that promise-breaking will generally be harmful, given the expectation of reliance on the promise, but in special cases will be justifiable.) In clearly exceptional cases it will not be justifiable on utilitarian grounds to adhere to the rule which gives priority to liberty, to allow starvation, or to keep promises come what may.

Rawls admits that his principles will not apply to all situations, particularly not those in which scarcity or extraordinary dangers would make the exercise of liberty a matter of no significance ${ }^{30} \mathrm{He}$ admits that a theory which offers rules of priority in assessing benefits tends to be caught between insisting that liberty is in principle a prior and overriding matter and admitting that there are situations in which goods are of primary

38. Of course the line between (a) inadmissible, mistaken conceptions of benefit and (b) the admissible range of views about benefit is itself a fuzzy line. Anti-Utopian novels by Orwell [1984 (1949)] and Zamiatin [We (1924)] illustrate that there are easy examples of inadmissible conceptions. Furthermore, disputants who hold different admissible views will each regard the other as mistaken and try to persuade the other of his mistake.

39. J. RAWLS, supra note 1, at 235-42 (1971). 
importance. ${ }^{40}$ Utilitarianism is not caught up by this seeming paradox since it rests only on the situationally variable notion of benefit. Exceptions to the liberty principle are just those cases in which the benefits to be gained by pruning liberty to prevent material harm are overriding.

(3) The problem with utilitarianism, according to a different criticism, is not that it ignores active benefits or that it undervalues them. Rather the problem is that a utilitarian decision-maker thinks of himself as allocating benefits, regardless of the nature of the benefits. To take liberty (or rights)" seriously is not to think of them as something dispensed but as a limitation on the kinds of allocations permitted to the decision-maker. They are a veto which individuals have over the range of possible decisions.

It is hard to see what difference this criticism suggests either in the way decisions would be made or in the way decision-makers would generally think of their powers. On either the recommended theory or utilitarianism the decision-maker intervenes to affect persons' lives. A decision to secure conditions for the exercise of freedom is still a situation which is affirmatively brought about. Respecting liberty or rights is not the same thing as refraining from a decision, not the same thing as refusing to make a decision. By refusing to act he may abet the infringement of liberty. If the practical point of the objection is not to recommend inaction by the decision-maker when rights are at stake, perhaps it is a point about the "demand" character of the decision. Perhaps it says that a decision to respect rights or secure liberty is incumbent on him in a way that the decision to maximize benefits is not. But this is a distinction without practical effect since the general principle of utilitarianism already makes it incumbent on the decision-maker to maximize benefit.

Lying behind the objection is a sound observation, but one which has little to do with the merits of utilitarianism. The point is not about alternative standards or points of view for the decision-maker, since on either theory he must not think of himself as inactive when rights are claimed and since (as I have argued) a utilitarian position may adequately capture his stance as a defender of liberty. Rather the point is about the attitude of the person affected by his decision. From this point of view, certain conditions which we call "rights" seem so clearly essential to the exercise of personality ${ }^{42}$ that the decision-maker seems to have no choice but to

40. I do not mean to suggest that Rawls himself is either unaware of this possible dilemma or caught in it. He argues that limitations on liberty in societies that are not well-ordered are limitations which proceed from (and can be justified by appeal to) the principles of justice themselves. "Unfortunate circumstances and the unjust designs of some necessitate a much lesser liberty than that enjoyed in a well-ordered society." Id. at 243.

41. See note 27 supra.

42. I am using the notion of personality in Max Weber's sense of the "understandable motivations of the single individual." See H.H. Gerth \& C. Wright Mills, From Max Weber: Essays in Soclology 55 (1958). I do not intend to say that Weber subscribes to the view suggested about the 
convey these benefits. But this is an illusion. In hard or easy cases, the decision-maker chooses. The question is not whether he chooses but how.

(4) A final objection which may be raised is a psychological point and not a philosophical one. The point is that decision-makers who think of themselves as weighing benefits are likely to undervalue liberty and that decision-makers who think of liberty or rights as an absolute veto over conflicting benefits will in fact appropriately weigh so-called active benefits and respect rights. It follows that the advocacy of a self-conscious utilitarian approach to decision will lead judges to make erroneous decisions.

This is a strange argument. On one level, it is irrelevant since we are investigating the proper standards which ought to govern decision-making, the standards which are implicit in moral reasoning. ${ }^{43}$ The notion that a decision-maker may abuse those standards is irrelevant. We are not investigating whether false standards ought to be promulgated among decisionmakers as a prophylactic against abuse. In other words, we are concerned with the standards themselves and not with an examination of the benefits and harms of promulgating those standards.

Beyond this, the psychological assumption is unconvincing. It presumes that we know more about how moral decisions are made than we really know and that we know how judges would use or abuse particular standards. Furthermore, if the assumption about how judges apply standards were true, it would go far to undermine confidence in the use of any standards in moral judgment, whether they were the standards of the liberty-theorist or the utilitarian.

\section{Utilitarianism AND Judicial Decisions}

In discussing theories about liberty, we have noticed some special features of judicial decision-making. Unlike the ordinary person in moral situations, a judge's decisions frequently affect liberties and ostensible rights. The objections of the liberty-theorist are raised most interestingly with regard to the decisions of public officials. In this section, I shall apply our general account of a utilitarian theory based on the notion of benefit to the decisions of judges.

There are constraints on judging which are not moral constraints; among these are formal and procedural rules. But all judicial decisions affect persons in beneficial or harmful ways. Decisions affect not only petitioners before a court, but also persons who will have to modify their behavior in accord with law as it is set in specific decisions, and even

relation of liberty and personality.

43. We are investigating the proper standards which "ought" to govern decision-making, not from the particular point of view of the theorist's personal preferences, but from the point of view of what is implicit in the practice of moral discourse. 
persons who merely have a general interest in the stability of government. In this sense, judicial decisions are necessarily moral decisions ${ }^{44}$ and a general account of moral justification applies to them as well. And yet, at the same time, a judge's decisions have various kinds of beneficial and harmful effects which an ordinary person does not have to take into account. For example, a decision which may maximize benefit in a particular case may also (a) cause havoc in the legal system and (b) conflict with the formal criteria (Hart's secondary rules) of judicial decision-making. In addressing these distinctions, we must ask first how, in practice, a judge would go about making decisions in a utilitarian way.

First of all, note that in every moral decision some benefits and harms are direct while others are indirect. The direct effects are not necessarily weightier, and the indirect effects may be overriding in determining the merits of an action. For example, White's decision to break a promise to Brown in order to be available to perform a service for Green has the direct consequences of harm to Brown (detrimental reliance, loss of the object of the promise, etc.) and benefit to Green. Indirect consequences are of several kinds. Some are consequences for the immediate participants, others are not. The decision may damage the friendship between White and Brown, it may create a friendship between White and Green, or it may undermine White's trust among his friends generally. Other consequences are more remote. The decision, if widely known, may set a precedent for others in the community, may make persons generally aware of and responsive to the plight of persons like Green, and may weaken the institution of promise-keeping. Obviously, the claim that a particular consequence will be significant depends on the situation. ${ }^{45}$ The general point is that each of an indefinite array of consequences, near and remote, are appropriately raised, evaluated, and perhaps dismissed. The appropriate array of consequences to consider is not defined as (a) the consequences of breaking promise $\mathbf{X}$ to Brown in order to, etc., but as (b) the consequence of White's breaking promise $\mathrm{X}$ to Brown in order to, etc. Who the decision-maker is and how he is situated are often critically important in an assessment of consequences.

The decisions of a judge in court necessarily have wider consequences than the moral decisions of a person who does not have an institutional role. A decision that Jones is liable in damages to Kramer is altogether different from the decision (and implementing action) of Robin Hood in taking a sum equal to the assessed damages from Jones and giving it to Kramer, even when the relationship and mutual claims of Jones and Kramer are in both cases the same. As a utilitarian, one is not concerned with

44. See section I supra.

45. For example, it is often implausible that breaking one's word will significantly damage the institution of making promises. 
the consequences attributable to the abstraction "deciding to transfer a sum as reimbursement for injury from Jones to Kramer" but with the consequences in the concrete situations of (a) Judge Tuck deciding in the state court of appeals that . . . and (b) Robin Hood deciding to steal from Jones, etc. The difference in context necessarily means that what I have called the indirect consequences will make a significant and possibly decisive difference between the two decisions. Judge Tuck, like Robin Hood, will consider as one element the history of relations between Jones and Kramer, the harm caused by Jones to Kramer, and the probable effect on Jones and Kramer of an award of damages. But there are other important elements present in Judge Tuck's considerations and not in Robin Hood's. Among them are the effect in general on business practices of parties relevantly like Jones and Kramer, the effect on other jurisdictions and other kinds of cases, the effect on public perception of judges and confidence in the law, and so on.

Judges, like others who administer and determine the law, affect society in ways that private moral decision-makers cannot. Even a highly visible, well-publicized private moral decision has no direct effect on other decisions in similar cases. It is not binding on other decision-makers however much it may have the force of example. Most legal systems, however, follow a system of precedent whereby a decision, once made, is binding on similar cases (the doctrine of stare decisis). Consistency is not an inherent feature of the collection of private moral decisions by various decisionmakers or even by a single one. Consistency is, on the other hand, required of a legal system; rules enforced on behavior in a particular system or jurisdiction must be mutually consistent. This does not mean that there are no lapses in consistency but that it is incumbent on judges to reconcile decisions with the body of existing law.

I shall assume without argument that there is a general benefit in having a system of some public rules which are highly predictable and applied consistently, rather than a system of ad hoc decisions without discernible guidelines for future behavior. In other words, I assume it is desirable to have a system of laws over and above a system of private moral decision and action. ${ }^{46}$ The consequence for the role of judges is that they must regularly attend to two kinds of beneficial/harmful consequences of any decision. The first kind involves both direct and indirect benefit and harm to those who have relied on existing law in its consistency and stability. Whenever a judge contemplates a decision which changes the law, he is likely to impinge upon and damage the interests of those who have relied on standing law. There are many general doctrines in the law which are

46. Presumably an anarchist would disagree. Hobbesian arguments about the desirability of coerced order can be used to sustain the point. 
designed to minimize this kind of dislocation. The doctrine of precedent, the doctrine that decisions should generally not be given ex post facto application (assuring that those affected by changes in law be in a position to be warned of the change), and the doctrine that a decision which represents a change be made on the narrowest available grounds are examples. ${ }^{47}$ The generally beneficial consequences which are at stake when these doctrines are applied are reliance on settled law and consistency of treatment between parties to old and new cases. ${ }^{18}$ The second group of beneficial and harmful consequences are the effects of a decision on the parties to the case, that is, direct and indirect benefits and harms to the petitioner and the defendant. In many cases, of course, a decision advances both groups of considerations at once; by adhering to settled law, a judge may benefit the parties to the case. In many hard cases, however, there is conflict; in these cases, considerations of justice to the parties to the case must be weighed against unsettling the law. ${ }^{49}$

The array of considerations of benefit and harm which a judge must consider is still more complicated than has been indicated. In every decision, a judge sets a rule of law to govern the case before him and relevantly similar cases. Among the benefits and harms which he affects and must weigh are not only (a) benefit and harm to parties at issue and (b) general considerations of predictability and reliance on settled law but also (c) benefit and harm to all subsequent parties likely to be affected directly or indirectly by the decision. Richard Wasserstrom, in his book, The Judicial Decision, ${ }^{50}$ gives the example of a foreclosure proceeding by a wealthy mortagee against an improverished widow. From the perspective of Robin Hood, the widow's benefit seems to outweigh any possible benefit to the mortagee in allowing foreclosure. A judge, on the other hand, must consider the general effect of the practice which he is setting up by the rule of his decision. He must anticipate, for example, that mortgagees, knowing that enforcement of mortgage terms will be hampered in similar cases, will refuse to give such mortgages with the predictable consequence of great harm to the class of widows in similar straits. ${ }^{31}$

A judge will characteristically have to be more conservative than a

47. See A. Bickel, The Least Dangerous Branch (1962) and R. Wasserstrom, The Judicial DECISION (1961).

48. R. WASSERSTROM, supra note 47, at 66-69. Wasserstrom lists other purposes like certainty and efficiency, id. at $60-66,72-74$, but I find it unconvincing that certainty is a separate virtue, distinct from reliance, or that efficiency is an independent virtue at all. In other words, there may be some comfort in knowing where one stands vis-a-vis a stable but unjust law but no comfort at all in knowing it will be applied efficiently.

49. I am using "doing justice to the parties" as a synonym for "maximizing benefit among the parties." Thus, I assume the arguments of previous sections have been accepted. The dilemma I am describing is the main subject of Wasserstrom's book.

50. R. WASSERSTROM, note 47 supra.

51. Id. at 141-45. 
private moral agent since considerations of kind (b) will count against decisions to change existing law and thereby disturb expectations built upon existing law. Considerations of kind (c) will in many cases, but not all, also have the effect of standing in the way of change. For example, the effect of refusing to enforce the terms of the mortgage in Wasserstrom's example is to damage future widows. A judge will do so reluctantly and will have to find countervailing benefits. On the other hand, in a case in which corporations limit their warranty coverage on products so that consumers cannot recover for defects, a change in the law which extends greater protection to consumers by outlawing such limitations may be justified in terms of the interests of parties to the case and of others similarly situated..$^{32}$

Wasserstrom's discussion of judicial decision-making is also concerned with the complexity of a judge's moral decisions. I shall clarify the theory I have been offering by comparing it with Wasserstrom's perceptive analysis. $^{53}$ Wasserstrom identifies two unsatisfactory procedures for judicial decision. The first is based only on considerations of stability and reliance. He calls it the model of precedent; it gives priority to those considerations which I have labelled kind (b). The second model is based on considerations of fairness and justice to the parties to the immediate case (considerations of kind (a)); Wasserstrom calls it the equity model. Wasserstrom concludes that a utilitarian committed to weighing benefits and harms in the individual decision will follow the second model. He argues that a modified two-level utilitarianism is needed to combine the virtues and avoid the defects of the two procedures: at the first level the judge consults established rules, and at the second he evaluates the rules in terms of their general effect in advancing the purposes of law. ${ }^{54}$

Wasserstrom's recommendation is ambiguous. Either he is proposing a procedure which will generate the same decisions as the straightforward utilitarianism advanced above because it will ultimately involve considerations of kinds (a), (b), and (c) or he means that extra deference should be paid to precedent considerations over and above whatever benefits are to be achieved by such deference. It is hard to see what can be said for the second position. By definition, no benefit overall can be gained by instructing a judge to follow such an injunction except on the theory, rejected above, that judges be instructed to follow a different theory from the sound procedure they are expected to follow..$^{\text {ss }}$ It is easy to see where Wasser-

52. See Henningsen v. Bloomfield Motors, Inc., 32 N.J. 358, 161 A.2d 69 (1960), as discussed in R. DwORKIN, supra note 1, at 23-24.

53. Wasserstrom's entire book is about the three models of judicial decision-making, the defects of the first two models, and the virtues of a "two-level" procedure.

54. R. WASSERSTROM, supra note 47 , at ch. 7.

55. See sections I and II supra. 
strom goes wrong. He assumes that a utilitarian who simply considers the consequences of his decisions will be limited to considerations of kind (a), what he calls equity matters. But this is not so because the judge as utilitarian will be aware of his institutional role. As such, he will have to consider a range of benefits and harms beyond those which Wasserstrom calls equity matters, the range which includes (a), (b), and (c).

Therefore, a utilitarian theory of judging will not cause havoc because it will not involve ad hoc decisions made solely on the merits of claims by particular petitioners and effects on particular first parties. The misunderstanding that it would do so seems to be the basis of Wasserstrom's objection. A different criticism is suggested by Dworkin. It is that, whatever the merits of utilitarianism as a moral theory may be, it is not the job of judges to rectify misallocations of benefit and harm. This is the job of legislators. The job of judges, unlike that of legislators, is to apply laws and not determine policy. ${ }^{56}$

This argument has both a crude and a sophisticated form, although Dworkin offers only the latter. In its crude form, it is the theory we were able to reject above, namely that legislators have followed and should follow a strict decision procedure whereby correct answers are deduced from existing law. A sophisticated form is that it is not the job of judges to formulate and implement policies but only to safeguard principles of justice by making secure the rights of individuals. The distinction between policies and principles is at the heart of Dworkin's challenge to utilitarianism. A policy, for Dworkin, is a standard which sets out as a goal "an improvement in some economic, political, or social feature of the community." ${ }^{37}$ A principle is a standard which sets forth "a requirement of justice or fairness or some other dimension of morality."

Principles are propositions that describe rights; policies are propositions that describe goals . . . . I shall distinguish rights from goals by fixing on the distributional character of claims about rights, and on the force of these claims, in political argument, against competing claims of a different distributional character . . . A goal [unlike a right] is a nonindividuated political aim, that is, a state of affairs whose specification does not in this way call for any particular opportunity or resource or liberty for particular individials. ${ }^{30}$

I shall try to show that it is not obvious why this is offered as an alternative to utilitarianism ${ }^{80}$ or why it would in practice generate different results. In the language of benefit and harm, we may say that the term

\footnotetext{
56. R. DWORKIN, supra note I, at ch. 4.

57. Id. at 22 .

58. Id.

59. Id. at 90-91.

60. See id. at vii.
} 
"rights" identifies particular ways in which persons may be significantly harmed or benefited. These are harms and benefits so significant that (a) each person may think of them as conditions to which he is entitled and (b) only in exceptional cases can they outweigh other kinds of benefits and harms. Thus a utilitarian judge will give this class of benefits and harms a natural priority over others, not because they are expressed in principles rather than policies, but because they are weightier benefits.

One rebuttal to this argument is that the utilitarian practice does not guarantee that each person's rights will be protected while such a guarantee is an essential part of Dworkin's theory. While this seems true on its face, there is a fatal difficulty. According to Dworkin, the only guaranteed rights are institutional ones (as opposed to background rights) and concrete ones (as opposed to abstract rights). ${ }^{61}$ What does this mean? Among other things, it means that whether one has a right which must be respected depends on an assessment of the particular situation in which the right is claimed. But this is no more of an assurance than the utilitarian was willing and able to give in saying that rights are labels for benefits of supervening weight prima facie but that they must be assessed in particular contexts against competing benefits of comparable weight.

A different argument for Dworkin's position is that the contrast between rights and other benefits is so great and so clear that the utilitarian notion of a weighing or balancing is a misrepresentation of the process of decision. But the contrast is least clear where it is most needed, in hard cases. To be sure, Dworkin is correct that in ordinary cases decision-makers ought not to prefer policy to principle since this seems to suggest that they may disregard rights of persons in effecting social or economic ends. But this is not a distinctive feature of the role of judges. It is the moral responsibility of all lawmakers. This is an abuse of proper decision-making no less when it is done by legislation than when it is done by a judge, and for the same reason. Thus, both legislators and judges must attend to principles as weightier considerations than policies, in general, because principles tend to reflect more important benefits. But when we attend to hard cases, the distinction between policies and principles does not seem more helpful than the instruction to look for the most important benefits. In hard cases, how do we know what is a principle and what a policy? That is, how do we know what rights persons have? Is universal education a policy or principle? Is it a right? Is providing minimal subsistence a policy or a principle? Do persons have a right not to be allowed to starve? Indeed, it makes sense to say that the protection of rights is itself a kind of policy, is a supervening policy for legislators and for judges and, further, that cases are often ripe for judicial decision when that supervening policy has

61. Id. at 93 . 
not been properly respected by legislators.

To summarize these criticisms, it is hard to see how Dworkin's theory achieves clarification of issues that the utilitarian theory fails to achieve. If the distinction between policies and principles (between goals and rights) is to have a special use, it must give us a special identifying mark for rights so that we can recognize when a right demands recognition, i.e., just when a utilitarian weighing is said to be preempted by a right. But what makes a case controversial and difficult is precisely that we are unsure whether a benefit (usually an "active benefit") is so important that it overrides others and decide cases. Is, as we have said, the benefit of being educated at public expense through the age of seventeen a right supported by principle or a societal goal described by a policy? Is there a right to be considered for law school admission without consideration of one's race, or is it simply one goal among others to treat persons in this way?

We must not leave Dworkin without noting and borrowing an important insight about judicial decision-making. ${ }^{63} \mathrm{~A}$ useful definition of a hard case is that it is a case in which existing case law and statutes, the existing system of judicial precedents, and other immediately relevant rules of decision, tend to generate or fit a result which offends the judge's intuitions about benefit and harm. The legal system, as it comes down to the judge, is not merely a system of rules or a system of results, i.e., a system of particular allocations of benefit. It is also a system of reasons. The development of a legal system can be traced through the reasons which judges have given for particular determinations, reasons which embody many conceptions of human nature and therefore of the ways persons are benefited and harmed. The judge's matured decision must be informed by this history. His own determination of benefit and harm must be formed by consulting the justifications offered by other judges in other relevant opinions. He cannot (as a matter of logic) accept all mutually inconsistent arguments and all points of view, but he must mold his own consistent standards around those standards which embody for him the values of the legal system itself. As Dworkin says, this task is described as an ideal and demands a judicial Hercules. ${ }^{64}$

62. Dworkin discusses this situation. R. DwORKIN, supra note 1, at 223-39. Dworkin repeatedly concedes that the distinction between rights and goals is an elusive one:

It is hard to supply any definition that does not beg the question. It seems natural to say, for example, that freedom of speech is a right, not a goal, because citizens are entitled to that freedom as a matter of political morality, and that increased munitions manufacture is a goal, not a right, because it contributes to collective welfare, but no particular manufacturer is entitled to a government contract. This does not improve our understanding, however, because the concept of entitlement uses rather than explains the concept of a right. Id. at 90 .

63. DworkIN, supra note 1, at 105-30. The ensuing discussion in the text is my gloss upon Dworkin's story of a judicial Hercules and I am not at all certain he would accept my version of it.

64. Id. 
It is important to stress the magnitude and nature of the task for two reasons. First, the utilitarian principle must not be taken to license the judge's disregard of the history of decisions and opinions in his legal system. It does quite the opposite, since that history is the repository of conceptions of benefit and harm in the face of which he forms his own conception. The second reason is that a redirection of the law by a decision in a hard case is one which must be justified by appeal to reasons which meet commonly shared criteria of relevance, criteria developed and illustrated in that history. There is all the difference there could be between saying correctly that these standards are incumbent on a judge and saying that he is narrowly bound by past decisions.

\section{The Uses of a Theory of Decision}

A theory which explains the nature of standards of decision-making, particularly moral standards, is not necessarily a theory which dissolves dilemmas. It may map the rough terrain which a decision-maker must cross but it does not make the terrain smooth. It would be fine, we might have thought, for philosophers of law to make hard cases easy - or at least easier, to tell us how to find right answers. Perhaps they can do so by telling us that judges exhaust relevant law at a certain point and have license beyond that point. Perhaps, on the other hand, they can tell us where to find natural law or how to identify those rights which decide cases and are formulated in principles of law. ${ }^{.5}$

Utilitarianism not only disappoints all these expectations but explains why they must be disappointed. A decision about benefit and harm is a decision based on experience and ideally on wisdom, not a decision based on rules or license. A theory about decision cannot impart the stuff of experience, the appreciation of benefit and harm, any more than a philosophical theory about the nature of knowledge can impart knowledge about physics or history. Ironically (with some historical justification), utilitarianism is frequently criticized for having just such ambitions. We have seen that some forms of utilitarianism are vulnerable on those grounds.

The model of decision-making presented here allows us to give a synoptic account of well-known debates on constitutional theory. For example, such writers as Alexander Bickel and Felix Frankfurter, on one hand, and so-called judicial activists, ${ }^{86}$ on the other, debate whether it is generally wise for judges to intervene when controversial rights seem to be at issue

65. Dworkin does not claim to make hard cases easy in this way. See note 61 supra.

66. Compare, in this regard, A. BICKEL, note 47 supra, with any of several sympathetic discussions of the practices of the Warren Court or with the judicial opinions of William O. Douglas and Hugo Black. 
and when at the same time judicial vindication of such rights would significantly alter processes of social change. Bickel, following Frankfurter, commends what he calls the "passive virtues." ${ }^{67}$ He means that courts should be reluctant to take upon themselves the responsibility for changing social practices in unforeseeable ways. He adds that the framers of the Constitution anticipated such risks. ${ }^{88}$ One way of representing such debates (which the proponents may or may not find congenial) is to say that they are about what weight, as a general matter, is to be assigned to the benefits associated with the precedent model. They involve disagreement about the indirect or secondary effects of judicial activism. ${ }^{69}$

It is incorrect to think that self-conscious awareness of utilitarianism as a theory of decision is useless in such debates and, a fortiori, in resolving hard cases. Its use is elusive and indirect. It makes the discussant or judge aware of the standards of debate and the criteria of evidence. It makes explicit the process of fitting a decision within a general and publicly defensible theory of benefit and therefore of human nature.

67. A. BiCKEL, supra note 47 , at 200 .

68. See id. at 200-07.

69. A secondary effect is a kind of indirect effect on the institutions of law and society. 
$$
\text { . }
$$ 